\title{
Technogenic Deposit Reclamation as an Environmental Protection Factor
}

\author{
Kaerbek Rafkatovich Argimbaev \\ Saint-Petersburg Mining University, 21 Line V.O., 2, 199106, St. Petersburg, Russia Federation \\ diamond-arg@mail.ru
}

\begin{abstract}
Decrease of the industrial waste amount and thus, environmental enhancement in ferrous and nonferrous metallurgy is closely interlocked with the problem of the raw material integrated use. In most cases, particular components of the ores fed to metallurgical processing become waste sources. Recovery of valuable components and disposal of bulk waste aiming to reduce production emissions is often followed by their transformation into products necessary for the industrial sector. Tailing dumps have accumulated a plenty of different components which cause significant changes in the hydrochemical conditions of a large area. It leads to the deterioration of the reductive-oxidative situation in the area of a dump site location increasing reduction processes due to aeration worsening and increased content of organic matter, to changes in aggregate state, structure, physical condition, permeability and strength of surrounding rocks.
\end{abstract}

Key words: Tailing dumps, hydrochemical mode, waste dump, reductive-oxidative conditions, permeability, physical condition

\section{INTRODUCTION}

Prevention of environmental damage during complex processing of raw materials includes decreasing the harmful impact of the disposed waste on water, air, land areas (arable land, forests, pastures, areas for municipal and industrial construction) within the metallurgical works location.

According to the calculations made for certain Ural ferrous and non-ferrous metallurgical works (Russia), the share of the nature-protection effect makes up 10\% and is achieved by the integrated use of raw material. Thus, it is an important environmental protection factor that allows utilizing industrial waste (Argimbaev, 2018; Pashkevich and Petrova, 2015).

Technogenic deposits, formed by mining waste, may contain the waste of both extraction and metallurgical industry. They may comprise dumps and heaps of out-of-balance ores, mineralized rocks, slag and ash disposal areas, mine openings, active and preserved sludge and tailing dumps of neutralization stations, ore-dressing mills and other facilities (Argimbaev, 2016; Argimbaev and Kholodjakov, 2016; Fomin, 2016).

More than 70 thousand hectares of agricultural land are occupied by waste piles and tailing dumps Fig. 1. Since, the waste amount will be continuously growing, the area for their storage may drastically increase, both environmental pollution and economic losses will grow immeasurably.

Long-term operation of tailing dumps has a significant impact on the geological environment
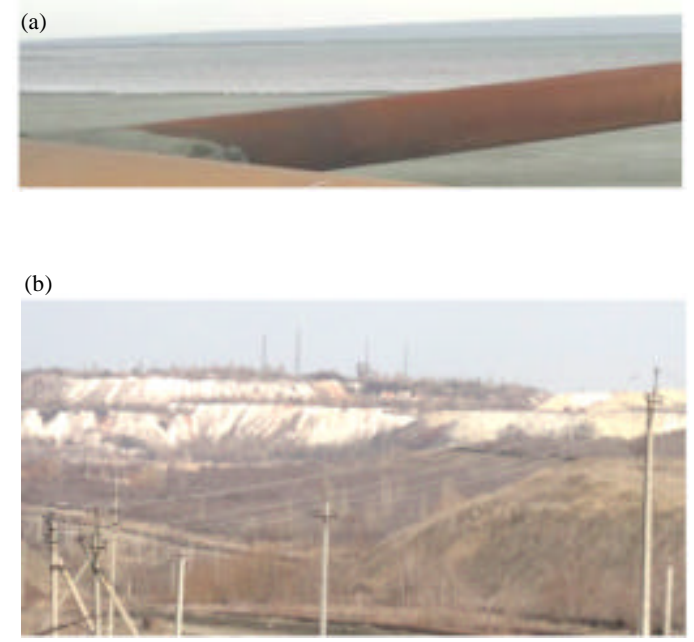

Fig. 1: Technogenic deposit kinds: a) A tailing dump and b) Overburden rock dumps

including rocks positioned under dumps in the areas of underflooding or backwater beyond the dump contour. The last case is caused by the fact that underflooding is accompanied by significant change in hydrochemical conditions, often within considerable areas (Anishchenko, 2009; Danilov et al., 2015).

Since, rock properties change in new technogenic, hydrodynamic and hydrochemical conditions, the forecast of rock transformations over time and space should 
be correlated with the dynamics in the underground water chemical behaviour (Kovshov and Barkan, 2016; Burmistrov et al., 2017).

The mechanism responsible for the formation of new technogenic hydrochemical conditions within the tailing dump contour may be conditionally presented as separate cycles in space and time.

The first cycle comprises free vertical filtration of industrial effluents into rocks occurred in the aeration area. This cycle was sufficiently short, for example, for the tailing site at Magnitogorsk Iron and Steel Works (MISW) PJSC (Russia), taking into account the initial high level of underground water. The second cycle may be considered as the banked-up filtration phase which is featured by mixing industrial effluents with underground water. The third cycle comprises migration itself of the contaminants in underground water of the complete saturation zone. Contamination front is formed in the flow beyond the drain ditch contour. Thus, the issue of the technogenic deposit exploitation is of a high priority today in particular, to increase environmental safety.

\section{MATERIALS AND METHODS}

The formation of physical-chemical environment has different intensity inside and outside the tailing dump contour. Tailing dumps of MISW PJSC feature rapid increase of the underground water level inside their contours which is accompanied with mixing and formation of the single aquifer system that may be conditionally divided into two aquifers. The upper is limited by technogenic rocks sand, the lower by glaciolacustrine deposits. Primary deposits serve as a water-tight stratum for the whole system. Chemical composition of industrial effluents of the MISW PJSC tailing dump features organic and inorganic components. The main pollutants are: organic diesel fuel containing diesel oil and kerosene and inorganic sulphur, fluorine, zinc, etc.

Destruction of organic substances in industrial effluents is a quite complex redox process, the nature and dynamics of which depend on a number of chemical and microbiological factors. Chemical oxidation of organic compounds depends on the amount of free oxygen entering the water-rock system. Since, the possibility of the atmospheric oxygen entry is not the same in different dump sections and in a vertical direction along its pattern, a number of zones may be distinguished by the intensity of reductive-oxidative conditions.

Organic components undergo intensive chemical oxidation in the upper zone of the tailings pond, the capillary saturation zone and the near-surface part of the aquifer limited to technogenic sand where the effect of oxygen-enriched precipitation is considerable Fig. 2.

Oil products are oxidized most active in the dump pond area during the summer period due to interaction with atmospheric air and solar irradiation. It is known that dry and slightly wet rocks have the highest sorption ability in relation to oil products contained in industrial effluents. As the water saturation increases in rock (including sand), sorption activity decreases relatively polar components of oil products. Water-saturated technogenic deposits adsorb only so-called "residual" amount of oil products as a liquid phase. This amount of petroleum derivatives is defined by their water solubility and the sorption ability of water-saturated technogenic sand. Since, "residual quantity" of both components is insignificant as compared to the component's content in technogenic water filtered through washed-up sand, excessive oil products are pushed into upper layers of the rock with lower humidity in aeration zone. This process takes place against the density convection caused by the difference between the oil product and water density and their poor miscibility. As a result, the level of capillary ascent where the layer is formed with the maximum amount of oil products, fluctuates. Such layers enriched with oil products are detected in technogenic sand directly above the groundwater level during the drilling by changing of the sand colour (it becomes black) and by the specific smell. Atmospheric oxygen access to this zone is hindered due to the oil product film in the capillary part of the technogenic aquifer. In the absence of oxygen and light, chemical oxidation of the oil products virtually does not occur. In this connection, a reduction zone is formed in the lower part of technogenic sand and in glaciolacustrine deposits of the tailings dump base.

Beyond the tailing site contour, lies an oxidative environment within the area of aquifer capillary ascent in glaciolacustrine deposits, since, this part of the section contains a free water-exchange area Fig. 2. Below the groundwater level, oxidative conditions are replaced by reductive ones due to difficult aeration Fig. 2. The thickness of the aeration area depends on the terrain and grain-size type of sandy and clay rocks. For example, an area may be swamped, if the upper part of glaciolacustrine deposits is formed by more argillous rocks and this area is at low orographic elevations. Accordingly, an area with reductive properties is raised. Thus, an oxidative environment within the dump contour is typical for the upper part of the pond area and the aerated part of technogenic sand up to the water level of the technogenic 


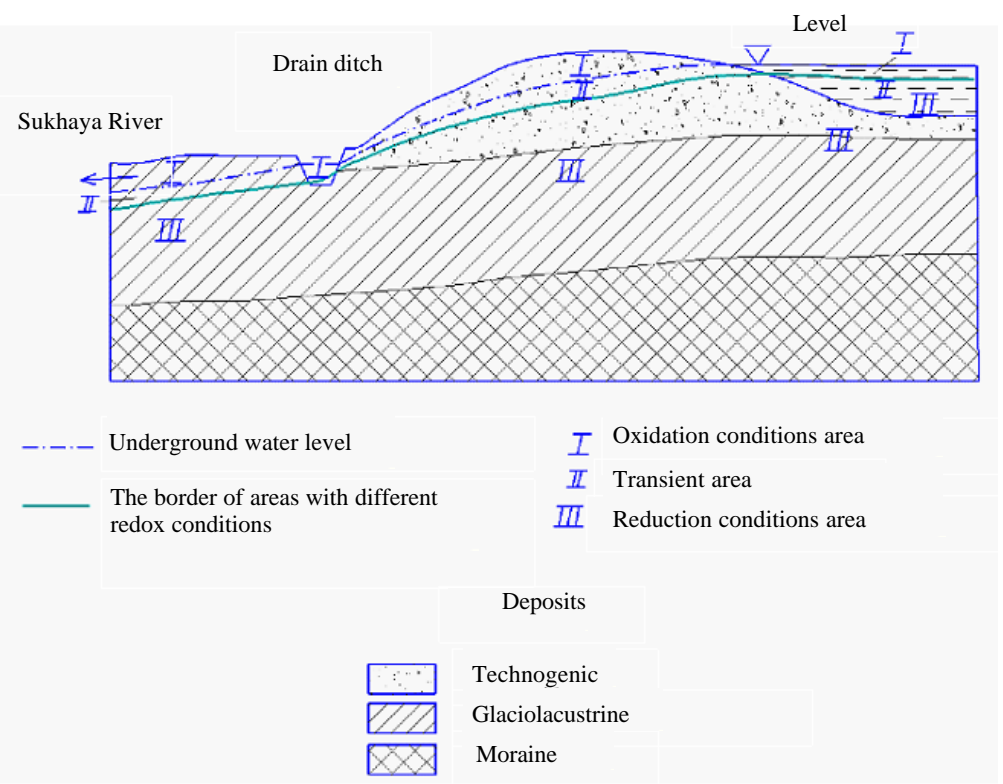

Fig. 2: Mapping of reductive-oxidative conditions within the tailing dump of MISW PJSC (Russia)

aquifer. Reductive conditions are formed within the entire layer of glaciolacustrine deposits located in the tailing dump base and in the watered part of technogenic sand.

Beyond the tailing dump contour, there is an oxidative environment in sandy and argillic rocks which are placed over underground water within the capillary biddix of the glaciolacustrine deposit aquifer. If they are located below the underground water level, the environment will be reductive.

The area of seasonal fluctuations of the underground water level may be considered as transient. Sukhaya River is a discharge area for the aquifer located in glaciolacustrine deposits. Reductive-oxidative conditions in the river water and its near-bottom part require additional study.

\section{RESULTS AND DISCUSSION}

Due to allocation of the areas with the different reductive-oxidative environment, it seems necessary to evaluate the change in the properties of rocks that form the tailing dump bed and a part of the glaciolacustrine deposit layer occurred beyond the dump contour.

Results of the test performed beyond the tailing dump contour indicate the existence of several zones in glaciolacustrine deposits. Division into different zones may be yet carried out on the basis of visual inspection over sandy and clay rocks occurred above and below the underground water level. These rocks over the ground water level are yellow-brown, yellow and reddish, they contain ochroid concretions and interlayers. Rocks gradually change their colour by depth, they become grey. Below the water level, grey colour prevails for rocks, they are bluish and blue-grey at a depth $4.0-5.0 \mathrm{~m}$.

When comparing the changes in the properties of sandy and clay rocks of different colours, occurred above and below the underground water surface, it was possible to make the following conclusions. The upper part of the studied deposits is more aggregated. They are often sabulous and loamy by their grain-size classification, more crumbling, cloggy. They usually feature lower humidity up to $30 \%$, more stable consistency, lower plasticity index (5-7) and higher filtration coefficient -0.05 to $-0.16 \mathrm{~m} /$ day. These deposits have the higher strength as compared with rocks occurred below the water level. There are the following strength parameters: adhesion is 0.019-0.068 $\mathrm{MPa}$ inner friction angle is $5-10^{\circ}$. Dispersivity increases for the rocks below the water level, according to grain-size classification, they are formed by the more loamy varieties, rock humidity is $40-60 \%$. Occasionally, consistency index exceeds 2 , it indicates an obviously unstable consistency, plasticity index reaches 29. Filtration coefficient is $0.04-0.009 \mathrm{~m} /$ day. Clayey rocks occurred below the groundwater level have the following strength parameters: adhesion is $0.018-0.025 \mathrm{MPa}$ inner friction angle is $0-4^{\circ}$.

Similarly, it is possible to observe the change in the colour of technogenic sand deposits. Yellow, yellow-brown sand is observed above the water level in 
the technogenic aquifer. It becomes black in the capillary ascent area and grey with dark, bluish intermediate layers below the groundwater level.

It is known that various minerals serve as qualitative indicators of the reductive-oxidative environment. Iron minerals take a special place among them due to their bright colour. Iron is one of the most common inorganic compounds capable to change its valence within redox potential which is characteristic for natural and technogenic water. The potential is set by the following system:

$$
\mathrm{Fe}^{2+}=\mathrm{Fe}^{3+}+\mathrm{e}
$$

It means that iron in a sandy and clay rock may be trivalent (oxidized) and bivalent (reduced). Minerals containing trivalent iron are yellow, brown, reddish coloured and may be easily identified by colour and ochreish nodules, spots and stains in the upper part of the glaciolacustrine deposit pattern containing free oxygen.

The difference in chemical properties of oxidized and reduced iron causes its behaviour in the groundwater. Oxidized trivalent iron easily undergoes hydrolysis and its content is negligible at $\mathrm{pH}$ values typical for groundwater. Iron transforms into oxide in the presence of oxygen in alkaline, neutral and even weakly acidic medium and is released from the solution in the form of the compounds consolidating the rock.

Existence of the upper zone in the aerated part of the glaciolacustrine deposit layer may be explained by epigenetic oxidation processes taking place in it. They result in rock cementation by iron oxides that make deposits more solid and aggregated. Significant changes take place in clay rocks in reductive conditions without atmospheric oxygen. In this case, oxidic compounds transform into protoxidic ones, crystallized iron becomes amorphous. Appearance of yellow-brown colour on grey samples, taken from the reductive zone and treated by hydrochloric acid, proves the presence of dissolved bivalent iron in pore water of glaciolacustrine clay deposits occurred below the groundwater level. In addition, hydrogen sulphide smell indicates the presence of iron sulphide in clay rock. Since, bivalent iron compounds are green, blue-grey, bluish, grey coloured, clay rocks in the lower part of the glaciolacustrine deposit pattern takes the similar colour.

Decreased strength increased dispersity of these deposits, most probably is associated with the decomposition of cementing compounds under reductive conditions. Thus, if sandy and clay rocks contain trivalent iron compounds, it becomes an oxidizer and is reduced to bivalent condition, at the same time, organic compounds are oxidized.

\section{CONCLUSION}

By research results, we have made a conclusion that argillic rocks of the tailing dump bed tend to gradually lose their strength during the dump operation life. It is especially obvious for the samples taken directly below the deposited sand.

Using of tailing dumps leads to the change of reductive-oxidative environment within the dump location increasing reductive processes due to poor aeration and increased content of organic substances that causes clay rocks to change their physical state, structure, physical properties, permeability and strength.

\section{REFERENCES}

Anishchenko, L.N., 2009. Bryoindication of the general state of atmosphere in an urban ecosystem: The example of the city of Bryansk. Russ. J. Ecol., 40: 247-253.

Argimbaev, K.R. and H.A. Kholodjakov, 2016. Tailings development and their utilization in the national economy. Int. J. Ecol. Dev., 31: 94-100.

Argimbaev, K.R., 2016. Monitoring of the industrial process impact on the environment in an open pit. Int. J. Ecol. Dev., 31: 23-28.

Argimbaev, K.R., 2018. Research of the dynamics of cryogenic processes in man-made deposits presented by dressing plant waste. J. Eng. Appl. Sci., 13: $1621-1623$.

Burmistrov, K.V., N.A. Osintsev and A.N. Shakshakpaev, 2017. Selection of open-pit dump trucks during quarry reconstruction. Procedia Eng., 206: 1696-1702.

Danilov, A.S., U.D. Smirnov and M.A. Pashkevich, 2015. The system of the ecological monitoring of environment which is based on the usage of UAV. Russ. J. Ecol., 46: 14-19.

Kovshov, S. and M. Barkan, 2016. Reduction of dust emission in transshipping processes at sea ports. Intl. J. Ecol. Dev., 31: 50-59.

Fomin, S.I., 2016. Foundations for technical solutions in organizing excavation of open ore pits. J. Min. Inst., 221: 644-650.

Pashkevich, M.A. and T.A. Petrova, 2015. The investigation of toxic waste burial polygon impact on the atmospheric air using lichenoindication method (Russia). Intl. J. Ecol. Dev., 30: 98-105. 